\title{
Defesa no Mercosul: avanços para a integração
}

\author{
Suzeley Kalil Mathias \\ Vanessa Braga Matijascic
}

\begin{abstract}
Resumo: O Mercosul, após 20 anos da sua criação, apresenta avanços no âmbito da defesa, mesmo não tendo enunciado esse objetivo na sua fundação. Trata-se de um dos mais sensíveis temas da política de um país. Assim, o caminho para a confiança mútua regional, iniciado com o Mercosul, segue com a Unasul e seu Conselho de Defesa. Tais mecanismos representam uma condição necessária para edificar bases sólidas de defesa e consolidar a autonomia sub-regional.
\end{abstract}

Palavras-chave: Defesa; Integração Regional; América do Sul.

\section{Suzeley Kalil Mathias}

Professora de Relações Internacionais da Universidade Estadual Paulista "Júlio de Mesquita Filho" (UNESPFranca). Pesquisadora do Grupo de Estudos de Defesa e Segurança Internacional (GEDES).

\section{VANESSA BRAGA \\ Matijascic}

Doutoranda pelo Programa de PósGraduação em História da Universidade Estadual Paulista "Júlio de Mesquita Filho" (UNESP-Franca). Integrante do Grupo de Estudos de Defesa e Segurança Internacional (GEDES).

\section{Mercosul defense: advances in the integration}

\begin{abstract}
Mercosur, 20 years after its creation, presents advances in the field of defense, even though this goal is not stated in its foundation. This is one of the most sensitive issues of a country's politics. Thus, the path to regional mutual trust, begun with Mercosur, continues with Unasur and its Defense Council. Such mechanisms are a necessary condition for building a solid foundation of defense and consolidating sub-regionalautonomy.
\end{abstract}

Keywords: Defense; Regional Integration; South America. 


\section{INTRODUÇÃO}

No dia 30 de novembro de 2011, a Declaração de Iguaçu completou vinte e seis anos, enquanto o Tratado de Assunção fez vinte anos em março. Em ambos os casos, trata-se da criação do Mercado Comum do Sul (Mercosul): na primeira, Argentina e Brasil deram início formal ao processo de integração aduaneira de ambos os países; no segundo, por meio da incorporação de Paraguai e Uruguai, formou-se o Mercado Comum do Sul.

Pela análise dos documentos mencionados, conforme é possível verificar, entre os objetivos não estava a integração da área de segurança e defesa, sendo que para muitos sequer ultrapassaria os primeiros passos da integração comercial, como defendíamos catorze anos atrás (SAINT-PIERRE; MATHIAS, 1997). Naquele momento, tratávamos o tema com uma metáfora, comparando-o a Jeremias Pé de Barro (p. 88-90). Continuamos pensando que, desde seu nascimento até pelo menos seu décimo ano, o desenvolvimento do Mercosul deu-se em um ambiente muito semelhante ao enfrentado pelo profeta Jeremias. No entanto, ao contrário daquela circunstância, as bases da integração dos quatro países provaram ser aço pintado, pois, a despeito de enfrentar situações de quase desmantelamento do projeto, fazendo com que muitos o analisassem como inexistente ou virtual (CIENFUEGOS; SANAHUJA, 2010), ou ainda concentrando seus avanços na relação entre Argentina e Brasil, atualmente pode-se ver que esse projeto, apesar de constituído para o comércio, avançou para um processo de integração que abarca amplas áreas, entre estas, a de defesa.

Logo, após uma geração, defenderemos aqui que um dos maiores avanços do processo mercosurenho foi justamente na área menos provável, a da defesa. Também sustentamos que os ganhos nesse âmbito funcionaram como facilitadores em outras áreas, justamente porque representam, antes de mais nada, o crescimento da confiança entre os países, pois rompe com os segredos que marcam o tema mais sensível das políticas estatais, porquanto representa a publicidade dos mecanismos de uso da força legítima.

Nesse artigo, portanto, queremos responder à seguinte pergunta: Como um tratado cujo objetivo é a criação e desenvolvimento de um mercado comum entre Argentina, Brasil, Paraguai e 
Uruguai avança em campos não previstos desde seu início, como é o caso da defesa, ao mesmo tempo em que não atinge seu principal objetivo que se plasmaria na criação de um mercado comum?

Na consecução da resposta, dividimos o texto em três partes. Na primeira, depois de uma rápida discussão conceitual, buscamos apontar os principais avanços da integração no Mercosul, bem como os atritos para sua realização. Na segunda, iniciamos o balanço para a área de defesa, enquanto dedicamos o terceiro a uma incipiente comparação entre Mercosul e União Sul-Americana de Nações (Unasul).

\section{MERCOSUL: COMÉRCIO OU INTEGRAÇÃO?}

\subsection{Uma discussão inevitável ${ }^{1}$}

Dos muitos pares usados pela ciência política, talvez o que congregue maiores controvérsias sejam os conceitos de segurança e defesa, cujo significado vai desde a sobreposição até o completo antagonismo. Por isso mesmo, aqui faremos uma breve discussão sobre tais conceitos com vistas a apontar nossa definição sobre tal par.

No âmbito continental, os termos defesa e segurança ganharam, entre a segunda metade do século XX e a primeira década do XXI, quatro significados quando considerados um em relação ao outro. Um primeiro tratamento os diferencia por âmbito geográfico. Nesse caso, segurança diz respeito a uma ação interna ao Estado enquanto defesa refere-se a uma ação externa. Um segundo significado associa defesa a determinada ação, enquanto segurança é uma percepção que, na maioria dos casos, antecede e embasa a ação de defesa. Uma terceira forma, bastante próxima da anterior, assume que a defesa é o meio pelo qual se atinge a segurança. Um exemplo seria a presença de bases policiais (meio) em locais de grande circulação, que inibiria crimes e contravenções (segurança). Por último, está aquela definição que busca a interação entre as três anteriores, muitas vezes chamada funcionalista. Para esta, segurança e defesa são fenômenos diferentes

1 A elaboração desta parte do artigo está fortemente baseada no trabalho Brasil: a Política Nacional de Defesa sob o filtro da Segurança, de Eduardo Mei e Suzeley Kalil Mathias, apresentado na VII Semana Iberoamericana de Seguridad y Defensa (FlacsoEquador. Quito, 7-9/6/2011). 
porque estão em âmbitos geográficos diferentes, representam atores e meios distintos, bem como são produtos de percepções diversas, conforme resume o quadro a seguir:

\section{Quadro 1 - Conceito funcionalista de defesa e segurança}

\begin{tabular}{|c|c|c|c|}
\hline Conceito & Natureza & AgENTES & AMBIENTE \\
\hline Defesa & Conflito/Guerra & $\begin{array}{c}\text { Forças } \\
\text { Armadas }\end{array}$ & Externo \\
\hline Segurança & $\begin{array}{c}\text { Desordem/ } \\
\text { Delito }\end{array}$ & Forças Policiais & Interno \\
\hline
\end{tabular}

Fonte: MEDEIROS FILHO, Oscar. Entre a cooperação e a dissuasão: políticas de defesa e percepções militares na América do Sul. Tese de Doutorado, DCP-FFLCH, USP, 2010, p. 44.

Neste trabalho, compartilhamos com a escola funcionalista a definição do par segurança e defesa, mas ampliamos o ambiente da ação para ambas as categorias, de modo a incluir tanto aquele externo quanto o interno ao Estado. Para nós, a diferença entre segurança e defesa está não apenas no ambiente da ação, mas também em sua natureza e no sujeito desta ação. Assim, tendo por base o quadro proposto por Medeiros Filho, para nós, defesa e segurança podem ser assim resumidas:

\section{Quadro 2 - Conceito funcionalista ampliado de defesa e segurança}

\begin{tabular}{|c|c|c|c|c|}
\hline Ação & NaTUREZA & AGENTES & $\begin{array}{c}\text { AMBIENTE } \\
\text { PRINCIPAL }\end{array}$ & $\begin{array}{c}\text { AMBIENTE } \\
\text { SECUNDÁRIO }\end{array}$ \\
\hline Defesa & $\begin{array}{c}\text { Conflito/ } \\
\text { guerra }\end{array}$ & $\begin{array}{c}\text { Forças } \\
\text { Armadas }\end{array}$ & Externo & Interno \\
\hline Segurança & $\begin{array}{c}\text { Delito/ } \\
\text { desordem }\end{array}$ & $\begin{array}{c}\text { Forças } \\
\text { Policiais }\end{array}$ & Interno & Externo \\
\hline
\end{tabular}

Um fator deve ser considerado quando se utiliza os agentes da defesa em questões entendidas como de segurança: sempre que isso acontece, explicita-se a demonstração de uma fraqueza ou incompetência do Estado para fazer frente àquilo que o ameaça.

Há de se considerar, todavia, que mesmo restringindo os conceitos ao exposto na tabela, segurança pode incluir diferentes campos do planejamento político, seguindo a proposta de definição dada pela Organização das Nações Unidas (ONU), a segurança humana, cujo significado pode ser tomado como: 
[...] a segurança humana se expressa na criança que não morre, numa doença que não se difunde, num emprego que não se elimina, na tensão étnica que não explode em violência, no dissidente que não é silenciado. A segurança humana não é uma preocupação por armas, mas pela vida e dignidade humanas [...] (PNUD, 1994, p. 22).

Esta é a mesma versão defendida pela Organização dos Estados Americanos (OEA), que ainda estabelece a defesa como meio de atingir e garantir a segurança. Essa visão amparada pela OEA, justamente por sua amplitude, pode levar à sobreposição de funções dos diferentes agentes, além de manter a subordinação da definição no âmbito das ameaças àquilo que é percebido pelos Estados Unidos da América como prioritário a ser combatido. ${ }^{2}$ Já a visão funcionalista ampliada, embora padeça da mesma restrição, isto é, da subordinação estratégica, distingue as arenas de ação para segurança e defesa, o que representa, para países como o Brasil e seus vizinhos, fator de grande importância.

A indistinção entre segurança e defesa pode ser vista como chave na garantia de maior autonomia aos governos, bem como às forças armadas ou policiais, no desenho e implementação de políticas tanto na área de defesa quanto na área de segurança. Isso porque, caso exista vazio ou sobreposição, caberia ao comandante em sentinela decidir tanto sobre o que ameaça e a quem como sobre qual seria o agente a ser utilizado no combate às ameaças identificadas.

Deve-se levar em conta que não existe um documento oficial do Mercosul que estabeleça como o conjunto dos países que o integram entende defesa e segurança, embora cada um desses países individualmente defina, com maior ou menor precisão, o par indicado. Assim, para os objetivos aqui perseguidos, adotaremos a proposição funcionalista ampliada como horizonte analítico.

2 Como vários especialistas atestam, a evolução do Mercosul é bastante influenciada pela relação da América do Sul com os EUA, o mesmo acontecendo no âmbito da defesa. No entanto, dado o espaço disponível, apenas mencionamos esta relação. Trabalhou-se detidamente a subordinação estratégica do Brasil em particular, mas também do Mercosul, em Brasil: interesse nacional e "novas ameaças". In: MATHIAS, Suzeley. K.; SOARES, Samuel A. (orgs.). Novas ameaças: dimensỗes e perspectivas. São Paulo: Sicurezza, 2003, p. 125-56. 


\subsection{O caminho regional}

Outro fator importante para a discussão anunciada diz respeito ao tipo de integração proposta pelo Mercosul. Parece haver consenso que o fenômeno integracionista propugnado pela América Latina nos últimos trinta anos buscou (no denominado regionalismo aberto ou novo regionalismo) os parâmetros da sua inserção no sistema internacional e manutenção da governabilidade interna. Conforme os mesmos analistas apontam, esse regionalismo aberto se esgotou quando confrontado pelo próprio estancamento ou crise, ${ }^{3}$ justamente porque enfatizou muito mais os mecanismos de "integração negativa", baseado na liberalização comercial (CIENFUEGOS; SANAHUJA, 2010, p. 88-91).

Ainda que o impulso inicial para a formação do bloco tenha sido a vontade política dos primeiros governos civis de Argentina e Brasil (1985-1988), complementados por Paraguai e Uruguai (1991), a crença na integração regional, em especial a do Mercosul, como produto dos processos de transição de governos autoritários, foi gradativamente perdendo terreno, como esclarece Visentini (2007, p. 82):

No início dos anos 80, o acercamento Brasil-Argentina viria a ser a espinha dorsal da integração regional, coroada com a constituição do Mercosul em 1991. Ao contrário do que se pensa, este acercamento não é resultado da democratização, mas fruto de um processo anterior e bem mais complexo e profundo, do qual a redemocratização constitui apenas um dos aspectos. Os primeiros acordos de cooperação foram firmados em 1979 e 1980, por Videla e Figueiredo.

3 O "estancamento" ou mecanismos de integração "em crise" são aqueles que surgiram e se desenvolveram por meio de adoção de uma estratégia regionalista pautada por proximidade geográfica, histórica e sociocultural ou de interesses comuns de interdependência, como o Mercosul e a CAN, mas que passaram por dificuldades que frearam o impulso integracionista em meados da década de 1990. Entre essas dificuldades retratadas por Sanahuja (2010, p. 90), o Mercosul é um exemplo de união aduaneira que se deteriorou como resultado da primazia de interesses domésticos, das convulsões financeiras que afetaram a América do Sul e das dúvidas crescentes sobre a rigidez do modelo e sobre o papel da liderança e do verdadeiro interesse do Brasil no processo. A CAN é descrita pelo autor como um mecanismo de estrutura institucional pouco eficaz, no qual os compromissos políticos não se cumprem. Além disso, caracteriza-se pela fratura crescente entre os países que o integram. Portanto, a crise enunciada é o resultado da soma dos fatores que diminuíram avanços integracionistas nos blocos sub-regionais, sejam eles problemas de escala interna ou meramente reflexos de uma conjuntura liberal na qual a América Latina e seus mecanismos de integração pretendiam estar adaptados. 
Nessa mesma linha, é bom lembrar do que se pode chamar de paradoxo da relação entre Argentina e Brasil, localizado na assinatura do Tratado entre Brasil e Paraguai para a construção da Usina de Itaipu, ainda no governo Geisel (1974-1979), quando os atritos entre aqueles chegaram à culminância, mas também foram o ponto de partida para o relaxamento da desconfiança mútua, especialmente no âmbito da segurança regional (CAUBET, 1989). ${ }^{4}$

Por isso, o esgotamento do modelo de integração negativa pode ser avaliado como um sintoma do aprofundamento do processo de integração política, adotando-se, portanto, caminho muito diverso daquele conhecido pela União Europeia e tido até muito pouco tempo como o melhor para o êxito de qualquer processo de fortalecimento regional. Isto é, o trilho da integração constituir-se-ia pelo estreitamento das relações comerciais e desde aí ir-se-ia ampliando para culminar na integração política, que, por sua vez, se completaria na adoção de uma política externa comum.

Contudo, se o principal objetivo do Mercosul é a integração econômica regional, representa principalmente um mecanismo de inserção no sistema internacional com relativa autonomia diante dos EUA. Este país, por sua vez, busca manter hegemonia a todo custo, razão pela qual o governo norte-americano lançou a Área de Livre Comércio das Américas (ALCA) e, ao mesmo tempo, favoreceu todos os mecanismos de vinculação bilateral com os países da América do Sul, deixando explícita a antipatia pelas escolhas brasileiras de fortalecimento dos mecanismos multilaterais e autóctones de integração.

Por perseguir novas formas de inserção sul-americana no sistema internacional, o Mercosul desde o início colocou-se apenas como centro propulsor de outras iniciativas de igual natureza, isto é, de melhorar as condições de mercado para os países sul-americanos no âmbito internacional. Em 1993, o lançamento da iniciativa da Área de Livre Comércio Sul-Americana (ALCSA) é o principal exemplo deste projeto. Em outras palavras, se como discurso o caminho da integração é comercial, este mesmo

4 Para uma discussão mais aprofundada, ver MATHIAS, Suzeley Kalil; GUZZI, André Cavaller; GIANNINI, Renata Avelar. Aspectos da integração regional em defesa no Cone Sul. Revista Brasileira de Política Internacional, v. 51, n.1, p. 70-86, 2008. 
imperativo funciona como uma estratégia para iniciativas em outras áreas (VISENTINI, 2007, p. 87).

Em resumo, defendemos aqui que o Mercosul não deixa explícito seus reais objetivos, que não estão na indicação do seu nome, pois se há grande cooperação comercial entre os países que o compõem, é também no âmbito do comércio que se conhecem os maiores entraves e as origens das sucessivas crises que sobre este mecanismo se abatem. Isso pode ser explicado, por um lado, pela forma como foi levada a cabo a política integracionista (regionalismo aberto), e, por outro, pela maneira como o Mercosul é encarado: menos como um projeto de integração e mais como um mecanismo impulsionador desta integração.

\section{MERCOSUL: INTEGRAÇÃO EM DEFESA}

Conforme mencionado, nenhuma das iniciativas de integração, especialmente o Mercosul, resultou no rompimento da subordinação estratégica da defesa ao poder hegemônico dos EUA. Ao contrário, é em períodos de distração, ou mais exatamente de profunda ignorância dos EUA relativamente à região sul-americana, que algum espaço é conquistado no intuito de afirmar os interesses regionais (TIBILETTI, 2004, p. 175). Esse é mais um motivo a apontar para a importância de avaliar a cooperação regional em defesa.

Desde os primórdios da Guerra Fria, houve incremento da aproximação entre as doutrinas militares da região. De fato, o inimigo comunista e a aceitação da hegemonia estadunidense no continente podem ser encarados como pilares fundamentais para a instalação de regimes burocrático-autoritários nos países da América do Sul (ROUQUIÉ, 1984).

Já ao longo dos governos fardados, a atuação da Escola das Américas, bem como a reprodução melhorada do ideário ali desenvolvido pelos responsáveis pela educação militar no Brasil, principalmente a incorporação daquele ideário por parte da Escola Superior de Guerra (ESG), levou ao aprofundamento das relações entre os agentes da defesa (RIAL, 1986), o que redundou na realização de projetos como o conhecido por Condor, recentemente descrito como "terrorismo internacional" por John Dinges (2005).

As alianças estabelecidas ao longo desses anos, entretanto, pouco têm a ver com aquelas já construídas desde meados da 
década de 1970. A primeira e mais visível diferença encontra-se na forma de encarar o outro, na clássica fórmula de Carl Schmitt, separando amigos de inimigos. Como já mencionado, Argentina e Brasil não apenas se encaravam como inimigos - as escaramuças eram os melhores exemplos - mas apontavam um ao outro como inimigo, tendo como palco provável para o conflito as fronteiras com o vizinho (OLIVEIRA, 2007).

Pelo exposto, desconsideramos como parte do mesmo projeto de integração as alianças citadas. Todavia, reconhecemos que estas foram uma base bastante influente para a aproximação e quebra da desconfiança. Nessa mesma direção, vale lembrar que a posição do Brasil, quando da guerra das Malvinas-Falklands, claramente favorável à Argentina, foi importante capítulo para a cooperação regional.

Não se deve entender cooperação em defesa como a criação de forças armadas comuns, como se fosse possível um exército, uma marinha e uma aeronáutica mercosurenhas. Apesar da proposta do presidente Hugo Chávez de criar um conselho de defesa que integrasse Argentina, Brasil e Venezuela, não se trata de criar uma espécie de "OTAN dos pobres", como alguém já chamou (FOLHA DE S. PAULO, 20/1/2006. p. A8). Ao contrário, o que se defende aqui, e as medidas adotadas apontam nessa direção, é que sem perder a identidade nacional, é possível superar a visão estreita sobre defesa para, tendo como método o mesmo adotado pelo Mercosul (a partir de um centro, incorporar cada vez mais temas e atores ao processo), evoluir para a formulação de interesses comuns e, portanto, para uma política de defesa cooperativa na região. Todavia, conditio sine qua non é a manutenção da autonomia nacional na formulação de políticas pelas nações reunidas, daí a grande dificuldade até aqui percebida.

Quanto à incorporação de áreas cada vez maiores na tentativa de realmente criar uma visão comum em defesa, a Argentina apresenta maior disposição do que o Brasil. Tanto é assim que, enquanto o primeiro faz acordos que estreitam cada vez mais as relações em defesa na região - como, por exemplo, a criação de força conjunta entre Argentina e Chile, anunciada há mais de um lustro (FOLHA ON LINE, 27/12/2005) -, o Brasil, apesar do 
discurso governamental, ainda alimenta desconfianças e procura postergar qualquer decisão nessa matéria. ${ }^{5}$

Ainda que a posição brasileira seja reticente, há várias iniciativas que exemplificam o acercamento cada vez mais amplo em defesa e segurança. A edificação do Atlântico Sul como Zona de Paz e Cooperação, livre de armas nucleares, por iniciativa brasileira e aprovada em 1986, e os acordos sobre controle do desenvolvimento nuclear desenhados entre 1986 e 1990, são os exemplos mais significativos (OLIVEIRA, 1998, p. 17).

Se estas medidas são mais importantes, há outras menos conhecidas cujo significado é muito mais profundo na formação dos agentes da defesa e, por isso, muito mais duradouras que aquelas estabelecidas no plano mais geral da diplomacia. Entre essas, as pioneiras foram realizadas pelas marinhas dos países do Mercosul, muitas vezes ampliadas para os vizinhos. Conforme Silveira (2010), entre tais iniciativas estão: Operação Fraterno (exercício conjunto entre as marinhas argentina e brasileira ocorrida periodicamente (intervalos entre 12 e 18 meses) desde 1978. Essas operações hoje incluem todos os parceiros do Mercosul, mesmo os sócios não plenos como Chile; Operação ARAEX (implementada desde 1992, é instrumento de aprestamento marinheiro sem paralelo no mundo); Operações ACRUX (têm como palco a hidrovia Paraguai-Paraná, realizadas por Argentina, Bolívia, Brasil, Paraguai e Uruguai); operações de treinamento de pilotos navais argentinos pela Armada brasileira, com a consequente economia de meios para ambas as marinhas e o compartilhamento de responsabilidades na defesa do espaço aéreo do Atlântico Sul, etc.

5 Esse comportamento é bastante claro no exército, conforme em diferentes oportunidades pudemos notar, enquanto na marinha e na aeronáutica há maior disposição para a integração das forças. No entanto, em nenhuma delas, nem no Ministério da Defesa, cogita-se um projeto de defesa comum, seja apenas binacional (com Argentina) seja multinacional (Mercosul). Já o Legislativo assinou, em 2002, protocolo de cooperação e defesa com a Argentina, o que mostra o descompasso entre os poderes, refletindo talvez as diferenças entre civis e militares em relação ao conhecimento da matéria, já bastante estudada pelos pesquisadores brasileiros. Um acompanhamento competente sobre a cooperação em defesa está em WINAND, Érica C. A. Defesa e diplomacia na administração de Fernando Henrique Cardoso (19952002): História e conjuntura nas relações com a Argentina. Tese de doutorado. FCHSUNESP, Franca, 2010. 
Como destaca Flemes (2004), desde os anos 1990, há uma crescente incorporação de atores e fóruns de discussão sobre defesa e segurança. No âmbito das operações militares conjuntas, elas são ampliadas geograficamente, abarcando todo o continente; e forças envolvidas, com a presença das marinhas, exércitos e forças aéreas dos países. Assim, por exemplo,

[...] na manobra Cruzeiro do Sul, as unidades argentinas, brasileiras e uruguaias utilizaram sistemas de armas coordenados, com o que se alcançou uma nova qualidade da cooperação e da sua aplicação prática em caso de emergência - como no caso de uma intervenção aprovada pelas Nações Unidas num país do Terceiro Mundo. No exercício militar Cabañas 2001 no Norte da Argentina participaram a própria Argentina, os Estados Unidos, o Brasil, o Uruguai, o Chile, a Bolívia, o Paraguai e o Peru. Durante esta manobra que englobou todo o continente americano, simulou-se uma guerra civil no Estado imaginário "Subistan", em que os soldados deveriam impedir a sua iminente desintegração (FLEMES, 2004, p. 3).

Cabe registrar também as reuniões de ministros da Defesa das Américas, em curso desde 1995. Embora uma iniciativa norte-americana, a existência dessas reuniões vem sendo avaliada positivamente pelos países da América do Sul, conforme mostra Radseck (2004), ao afirmar que Argentina, Brasil, Chile, Paraguai e Uruguai veem nelas um dos melhores espaços para a troca de ideias em matéria de segurança e defesa, promovendo o conhecimento mútuo entre os países e, por conseguinte, funcionando como mecanismo de quebra de suspeitas e de construção da confiança para as Américas.

Novamente Flemes (2004) informa que, principalmente entre meados dos anos 1990 e a criação da Unasul (2008), é visível o crescimento da quebra da desconfiança em defesa pela adoção de medidas comuns entre os países do Mercosul ampliado, ${ }^{6}$ tais como:

[...] a resolução de conhecidos conflitos fronteiriços, a ratificação dos acordos sobre o controle de armas atômicas, biológicas e químicas, a publicação de livros brancos militares, orçamentos de defesa mais transparentes, assim como uma nova qualidade na cooperação em política de segurança entre as Forças Armadas sul-americanas, parcialmente conduzida por civis (FLEMES, 2004, p. 6).

6 Aos quatro países que fazem parte do Mercosul, somam-se aqueles que ainda não foram considerados membros plenos, como Chile, Bolívia e Venezuela. 
Em síntese, o Mercosul, nele incluindo o Chile, está cumprindo o objetivo não revelado de abrir espaços para maior integração regional em torno de questões tão variadas quanto é o comércio de bens e os entendimentos sobre defesa. Os empecilhos, entretanto, se são maiores em defesa, quando rompidos beneficiam a relação de confiança mútua entre os países, alimentando o entorno necessário para a convergência de posições políticas cooperativas. Por isso, é possível afirmar que no âmbito da defesa o Mercosul foi uma experiência bem-sucedida, ampliando os espaços para que a região possa ter uma visão comum daquilo que a ameaça e como enfrentar tais ameaças. Tanto isso parece verdadeiro que a instituição melhor sucedida na construção de um regionalismo mais amplo representado pela Unasul é o Conselho de Defesa Sul-Americano.

\section{MERCOSUL E UNASUL: UM BALANÇO}

Enquanto o Mercosul consolida etapas de integração, a diplomacia brasileira, nos primeiros anos da gestão do governo Luiz Inácio Lula da Silva, logo se encarregou de incentivar a reunião de outros países da América do Sul para uma integração mais ambiciosa, como exemplo dado no discurso ao Congresso Nacional em 2007: "Fizemos do entorno sul-americano o centro de nossa política externa. O Brasil associa seu destino econômico, político e social ao do continente, ao Mercosul e à Comunidade Sul-Americana de Nações" (LULA DA SILVA, 2007).

Proposta pelo Brasil em 2004, a Comunidade Sul-Americana de Nações (CASA) objetivava congregar em uma só aliança todos os países da América do Sul, efetivando o objetivo do Mercosul de funcionar como um centro aglutinador dos interesses regionais, como já mencionado. Para tanto, os países do subcontinente reuniram-se anualmente em Cuzco (2004), Brasília (2005), Cochabamba (2006), Ilha Margarita (2007) e Brasília (2008). Esta última reunião representou o ápice do movimento integracionista, e resultou na assinatura do Tratado Constitutivo da União das 
Nações da América do Sul, em 23 de maio de 2008. ${ }^{7}$ O objetivo geral da Unasul era estabelecer "um espaço de união" amplo com a finalidade de proporcionar melhores condições para a vivência democrática e a superação da pobreza, tendo como objetivos específicos:

a) o fortalecimento do diálogo político entre os Estados Membros que assegure um espaço de concertação para reforçar a integração sul-americana e a participação da UNASUL no cenário internacional;

b) o desenvolvimento social e humano com eqüidade e inclusão para erradicar a pobreza e superar as desigualdades na região;

c) a erradicação do analfabetismo, o acesso universal a uma educação de qualidade e o reconhecimento regional de estudos e títulos;

d) a integração energética para o aproveitamento integral, sustentável e solidário dos recursos da região;

e) o desenvolvimento de uma infra-estrutura para a interconexão da região e de nossos povos de acordo com critérios de desenvolvimento social e econômico sustentáveis;

f) a integração financeira mediante a adoção de mecanismos compatíveis com as políticas econômicas e fiscais dos Estados Membros;

g) a proteção da biodiversidade, dos recursos hídricos e dos ecossistemas, assim como a cooperação na prevenção das catástrofes e na luta contra as causas e os efeitos da mudança climática;

h) o desenvolvimento de mecanismos concretos e efetivos para a superação das assimetrias, alcançando assim uma integração eqüitativa;

i) a consolidação de uma identidade sul-americana através do reconhecimento progressivo de direitos a nacionais de um Estado Membro residentes em qualquer outro Estado Membro, com o objetivo de alcançar uma cidadania sul-americana;

j) o acesso universal à seguridade social e aos serviços de saúde;

7 Conforme no momento se dizia, a troca do nome de CASA para Unasul pode ter representado uma forma de expressar os receios de países como Venezuela e Argentina, que relativamente alimentavam desconfiança quanto às pretensões de liderança brasileiras. A CASA foi um projeto proposto pelo Brasil que, ao nomear dessa forma sua proposta de pacto regional, imprimiu o significado de aconchego e solidariedade que se tem em "casa". No entanto, sob a alegação de que tal palavra não possuía nenhum significado em espanhol, os demais países sul-americanos propuseram a mudança do acrônimo, aceito imediatamente pelo Brasil. 
k) a cooperação em matéria de migração, com enfoque integral e baseada no respeito irrestrito aos direitos humanos e trabalhistas para a regularização migratória e a harmonização de políticas;

l) a cooperação econômica e comercial para avançar e consolidar um processo inovador, dinâmico, transparente, eqüitativo e equilibrado que contemple um acesso efetivo, promovendo o crescimento e o desenvolvimento econômico que supere as assimetrias mediante a complementação das economias dos países da América do Sul, assim como a promoção do bem-estar de todos os setores da população e a redução da pobreza;

m) a integração industrial e produtiva, com especial atenção às pequenas e médias empresas, cooperativas, redes e outras formas de organização produtiva;

n) a definição e implementação de políticas e projetos comuns ou complementares de pesquisa, inovação, transferência e produção tecnológica, com vistas a incrementar a capacidade, a sustentabilidade e o desenvolvimento científico e tecnológico próprios;

o) a promoção da diversidade cultural e das expressões da memória e dos conhecimentos e saberes dos povos da região, para o fortalecimento de suas identidades;

p) a participação cidadã, por meio de mecanismos de interação e diálogo entre a UNASUL e os diversos atores sociais na formulação de políticas de integração sul-americana;

q) a coordenação entre os organismos especializados dos Estados Membros, levando em conta as normas internacionais, para fortalecer a luta contra o terrorismo, a corrupção, o problema mundial das drogas, o tráfico de pessoas, o tráfico de armas pequenas e leves, o crime organizado transnacional e outras ameaças, assim como para promover o desarmamento, a não proliferação de armas nucleares e de destruição em massa e a deminagem;

r) a promoção da cooperação entre as autoridades judiciais dos Estados Membros da UNASUL;

s) o intercâmbio de informação e de experiências em matéria de defesa;

t) a cooperação para o fortalecimento da segurança cidadã, e

u) a cooperação setorial como um mecanismo de aprofundamento da integração sul-americana, mediante o intercâmbio de informação, experiências e capacitação (Tratado Constitutivo da UNASUL, 2008).

Com os objetivos ora consignados, percebemos que a natureza desse novo mecanismo de integração não se assemelha ao 
processo de surgimento do Mercosul ou Comunidade Andina de Nações (CAN). Logo, não se trata de criar uma área de livre comércio que gradualmente atinja as etapas seguintes que culminam numa integração econômica e política. A Unasul já é constituída com a característica de ser um mecanismo dual: promoção e concertação política e mecanismo de integração econômica. Ademais, a integração econômica está dimensionada tendo em vista as possíveis facilidades proporcionadas pela decisão política em reuniões anuais e extraordinárias do Conselho dos doze chefes de Estado e de governo. Qualquer manifestação que coloque em xeque se o projeto da Unasul surgiu com a finalidade de substituir os outros mecanismos de integração existentes não é válida, pois, desde a primeira reunião, a CASA estabelece o seguinte:

O espaço sul-americano integrado desenvolver-se-á e aperfeiçoar-se-á impulsionando os seguintes processos: [...] O aprofundamento da convergência entre o Mercosul, a Comunidade Andina de Nações e o Chile, através do aprimoramento da zona de livre comércio, apoiando-se, no que for pertinente, na Resolução 59 do XIII Conselho de Ministros da ALADI, de 18 de outubro de 2004, e sua evolução a fases superiores da integração econômica, social e institucional (DECLARAÇÃO DE CUZCO, 2004 apud Revista de La Integración, 2008).

Para nossa discussão, interessa salientar que a defesa é lembrada como um dos objetivos específicos. Porém, não se quer atingir a integração em defesa, mas sim estabelecer "o intercâmbio de informação e de experiências em matéria de defesa", o que pode ser visto como um primeiro degrau para se construir um pensamento comum, este sim capaz de embasar a formulação estratégica comum, o que implicará, se e quando atingido, maior autonomia da região em matéria de defesa.

Tal como o afirmado para o Mercosul, pode-se dizer que o diálogo em defesa tem sido maior do que em outras áreas da Unasul. Corrobora essa ideia a criação, em 16 de dezembro de 2008, do Conselho de Defesa da Unasul (CDS), o qual, conforme a Declaração de Santiago (janeiro de 2009), tem por principal objetivo reforçar a América do Sul como uma Zona de Paz e Cooperação (UNASUL. DECLARAÇÃO DE SANTIAGO, 2009). Os objetivos específicos (num total de onze) sugerem que o desejo dos países membros é alcançar um entendimento em defesa que permita manter a 
Zona de Paz em detrimento de interesses dos países hegemônicos e, em largo prazo, estabelecer maior integração no âmbito de defesa, como informa o Art. $5^{\circ}$, da Declaração de Santiago:

a) avançar gradualmente na análise e discussão dos elementos
comuns para uma visão conjunta em matéria de defesa; b) pro-
mover o intercâmbio de informação e análise sobre a situação
regional e internacional, com o propósito de identificar os fato-
res de risco e ameaças que possam afetar a paz regional e mun-
dial; c) contribuir para a articulação de posições conjuntas em
foros multilaterais [...]; d) avançar na construção de uma visão
compartilhada sobre tarefas da defesa e promoção do diálogo
em cooperação, preferencialmente com os países da América
Latina e Caribe; e) fortalecer a adoção de medidas de fomen-
to da confiança e difundir as lições aprendidas; f) promover o
intercâmbio e a cooperação no âmbito da indústria de defesa;
g) fomentar o intercâmbio em matéria de formação e capaci-
tação militar [...]; h) compartilhar experiências e apoiar ações
humanitárias [...]; i) compartilhar experiências em operações de
manutenção da paz da ONU; j) intercambiar experiências so-
bre processos de modernização dos Ministérios de Defesa e das
Forças Armadas; k) promover a incorporação da perspectiva de
gênero em matéria de defesa.

A cooperação em defesa, objetivo de longo prazo, vem sendo facilitada também pela visão pragmática dos ministros da Defesa da América do Sul que incentivam maior cooperação física - por meio da Iniciativa para a Integração da Infraestrutura Regional Sul-Americana (IIRSA), um dos projetos melhor sucedidos na região (e de caráter técnico) - favorecendo a integração da indústria de defesa na América do Sul, além de contribuir para o intercâmbio de alunos e professores nas escolas militares, especialmente as de Altos Estudos.

Desde agosto de 2009, a presidência do CDS é exercida pelo Equador, cujos funcionários proporcionaram o que se pode avaliar como um dos maiores avanços no projeto da Unasul: a negociação da paz entre Colômbia, Equador e Venezuela. Assim, tal como defendido para o Mercosul, também na Unasul é na área de defesa que se pode notar os maiores avanços no processo integrativo.

Como informado, a Unasul foi o desdobramento de uma iniciativa brasileira de integração, cujo centro de irradiação foi o Mercosul, tendo explicitamente na política seu maior objetivo. São esses vínculos que permitem afirmar que o âmbito da 
defesa, político por excelência, apresentou resultados promissores. Conforme se pode argumentar, muito antes da própria criação do CDS, quando o Ministério da Defesa brasileiro era ocupado pelo embaixador José Viegas (2003-2004), se desejava tornar mais efetiva a aproximação em matéria de defesa. Por essa razão, as áreas industriais e de infraestrutura foram privilegiadas, porquanto tomadas como os melhores mecanismos para a construção da confiança e da edificação de uma perspectiva comum em segurança.

Reforçam essa hipótese as declarações dadas tanto pelo ministro Nelson Jobim, quanto por seu par argentino, ministro Arturo Puricelli, que assinaram vários acordos, entre os quais o de construção do avião KC-390, considerado sucessor do Hércules C-130. Esse avião, projetado no Brasil, deverá ser fabricado na Argentina com a colaboração de profissionais de ambos os países (DEF $n^{\circ} 7$, p. 98). Nas palavras de Jobim:

[...] o futuro é o grande desafio para os dirigentes de hoje. Devemos consumir nossas energias em sua construção [para isso] é fundamental ter uma base industrial de defesa comum, fundada na interdependência entre os países da região. É ela que aponta para a confiança e [portanto] para a segurança (DEF $\left.\mathrm{n}^{\circ} 7, \mathrm{p} .98\right)$.

Posição semelhante foi assumida por Puricelli:

[...] estamos trabalhando e planejando em função do desenvolvimento de capacidades e interesses estratégicos comuns, como os que temos entre ambos os países [Brasil e Argentina] e com os demais países que integram a região. [...] nossos interesses vitais são, precisamente, defender nossos recursos naturais; a produção de alimentos [...]; a água potável [...] e o espaço vital. Esses, sem dúvida, fazem com que nossos interesses vitais sejam os mesmos para nossa região e para toda a humanidade (DEF n 7, p. 100).

\section{CONSIDERAÇÕES FINAIS}

Em resumo, defendemos nesse artigo que o Mercosul vem sendo melhor sucedido em aprofundar a integração na área da defesa, área política por excelência. Como consequência desse sucesso, ampliando-o e aprofundando-o, foi planejada a Unasul, e em seu interior o CDS, uma das primeiras instituições criada no interior da união sul-americana proposta. A criação do CDS, ou a escolha da 
defesa como âmbito para o aprofundamento do diálogo regional, exemplificam o aprofundamento integracionista.

Por fim, se defendemos que há sucessos significativos no âmbito da defesa no interior do Mercosul, não podemos chamar esses avanços de construção da defesa cooperativa ou mesmo da integração em defesa. Há diferenças significativas - como, por exemplo, a formação dos militares e suas funções na defesa - que ainda impedem o avanço para além da construção da confiança, de olhar o outro como possível parceiro. Entretanto, por ser a defesa um tema político por excelência, irreversível quando aberto, defendemos que todo pequeno passo nessa área é um grande avanço para o fortalecimento dos laços regionais, fundamentais para a edificação sólida da integração regional.

\section{REFERÊNCIAS}

BRASIL. Ministério da Defesa. Secretaria de Estudos e de Cooperação. O Brasil no cenário internacional de defesa e segurança. Organizadores J. R. de Almeida Pinto, A. J. Ramalho da Rocha, R. Doring Pinho da Silva. Brasília, 2004. (Pensamento brasileiro sobre defesa e segurança; v. 2). Disponível em: <http:// www.defesa.gov.br/arquivos/colecao/brasil.pdf>.

CAUBET, Chistian. As grandes manobras de Itaipu. São Paulo: Acadêmica, 1989.

CIENFUEGOS, M.; SANAHUJA, J. A. (Eds.) Una región en construcción. UNASUR y la integración en América del Sur. Barcelona: Fund. CIDOB, 2010.

COMUNIDADE ANDINA. Revista de la Integración: Secretaria Geral da Comunidade Andina, n. 2, jul. 2008.

DEF. Desarrollo, Defensa, Energia, Medio Ambiente. Buenos Aires: Taeda, año 6, n. 69, mayo 2011.

DINGES, John. Os anos do condor: uma década de terrorismo internacional no Cone Sul. São Paulo: Cia. das Letras, 2005.

FLEMES, Daniel. Uma comunidade de segurança na América do Sul: notas teóricas sobre a cooperação na política de segurança entre a Argentina, o Brasil e o Chile. Buenos Aires: Resdal, 2004. 20 p. (Textos Membros Resdal). 


\section{LULA DA SILVA. Discurso do presidente da República no} Congresso Nacional ao ser empossado para o mandato 2007 - 2010. Presidência da República, 1\%1/2007. Brasília: MRE, 2007. Disponível em: <http://www.mre.gov. br/ portugues/politica_externa/discursos/discurso_detalhe3.asp?ID_ DISCURSO $=3010>$

MATHIAS, Suzeley Kalil; GUZZI, André Cavaller; GIANNINI, Renata Avelar. Aspectos da integração regional em defesa no Cone Sul. Revista Brasileira de Política Internacional, v. 51, n. 1, p. 70-86, 2008.

MATHIAS, Suzeley Kalil; MEI, Eduardo. Brasil: a política nacional de defesa sob o filtro da segurança. In: SEMANA IBEROAMERICANA DE SEGURIDAD Y DEFENSA, 7., 7 a 9 de junho de 2011, Quito, Equador. Anais... Quito, Equador: Flacso Quito, 2011.

MATHIAS, Suzeley Kalil; SOARES, Samuel Alves (Orgs.). Novas ameaças: dimensões e perspectivas. São Paulo: Sicurezza, 2003.

MEDEIROS FILHO, Oscar. Entre a cooperação e a dissuasão: políticas de defesa e percepções militares na América do Sul. 2010. Tese (Doutorado) - Departamento de Ciência Política, Faculdade de Filosofia, Letras e Ciências Humanas, Universidade de São Paulo, São Paulo, 2010.

OLIVEIRA, Eliézer R. Democracia e defesa nacional: uma agenda a partir do Poder Legislativo. In: OLIVEIRA, Eliézer R. (Org.).

Segurança e defesa nacional: da competição à cooperação regional. São Paulo: Fundação Memorial da América Latina, 2007.

OLIVEIRA, Maria Odete. A integração bilateral Brasil-Argentina: tecnologia nuclear e MERCOSUL. Revista Brasileira de Política Internacional, v. 41, n. 1, p. 5-23, 1998.

PROGRAMA DAS NAÇÕES UNIDAS PARA O DESENVOLVIMENTO. Human development report 1994. New York: United Nations, 1994. Availabre From: <http://hdr.undp. org/en/reports/global/hdr1994/chapters/>. 
RADSECK, Michael. El sistema interamericano de seguridad: ¿quo vadis? Posiciones del Cono Sur a la luz de la Conferencia Especial sobre Seguridad Hemisférica. In: CONGRESSO DA ALACIP, 2., 29 de setembro a $1^{\circ}$ de outubro de 2004, Ciudad del México.

Trabalho presentado... Ciudad del México: [s.n.], 2004. 40 p. Disponible en: <http://www.giga-hamburg.de_dl_download. php_d=_content_ilas_pdf_radseckalacip04>.

RIAL, Juan. Las Fuerzas Armadas: ¿soldados-políticos garantes de la democracia? Montevideo: Banda Oriental, 1986.

ROUQUIÉ, Alain. O Estado militar na América Latina. São Paulo: Alfa-Ômega, 1984.

SAINT-PIERRE, H. L.; MATHIAS, S. K. Reflexões sobre o MERCOSUL: unidade estratégica e cooperação militar. História, Franca, SP, v. 16, p. 83-105, 1997.

SILVEIRA, Cláudio C. A formação militar-naval Brasil-Argentina no contexto de cooperação no Atlântico Sul: visões sobre a situação regional. História, Franca, SP, v. 29, n. 2, p. 30-49, dez. 2010.

TIBILETTI, Luis. Antiterrorismo na América Latina. In: BRIGAGÃO, Clóvis; PROENÇA JR., Domício (Orgs.). Panorama brasileiro de paz e segurança. São Paulo: Hucitec, 2004. UNIÃO DAS NAÇÕES SUL-AMERICANAS. Tratado Constitutivo da União das Nações Sul-Americanas. Disponível em: $<$ http://www.pptunasur.com/downloads/tratado-constitutivoUNASUR.pdf>. Acesso em: 20 abr. 2012.

. Declaração de Santiago. Disponível em: <http:// www.cdsunasur.org/ images/stories/Creacion\%20CDS/ Declaracion_Santiago_\%20Chile_2009.pdf>.

VISENTINI, Paulo G. F. O Brasil, o MERCOSUL e a Integração na América do Sul. Revista de Estudos e Pesquisas sobre as Américas, v. 1, n. 1, p. 82-94, ago./dez. 2007.

WINAND, Érica C. A. Defesa e diplomacia na administração de Fernando Henrique Cardoso (1995-2002): história e conjuntura nas relações com a Argentina. 2010. Tese (Doutorado) - Faculdade de Ciências Humanas e Sociais, Universidade Estadual Paulista, Franca, SP, 2010. 